\title{
High quality single-crystal germanium-on-insulator on bulk Si substrates based on multistep lateral over-growth with hydrogen annealing
}

Hyun-Yong Yu, Szu-lin Cheng, Jin-Hong Park, Ali K. Okyay, M. Cengiz Onbaşlı, Burcu Ercan, Yoshio Nishi, and Krishna C. Saraswat

Citation: Appl. Phys. Lett. 97, 063503 (2010);

View online: https://doi.org/10.1063/1.3478242

View Table of Contents: http://aip.scitation.org/toc/apl/97/6

Published by the American Institute of Physics

\section{Articles you may be interested in}

Defects reduction of Ge epitaxial film in a germanium-on-insulator wafer by annealing in oxygen ambient APL Materials 3, 016102 (2015); 10.1063/1.4905487

Reduced pressure-chemical vapor deposition of Ge thick layers on $\mathrm{Si}(001)$ for $1.3-1.55-\mu \mathrm{m}$ photodetection Journal of Applied Physics 95, 5905 (2004); 10.1063/1.1699524

Effects of hydrogen annealing on heteroepitaxial-Ge layers on Si: Surface roughness and electrical quality Applied Physics Letters 85, 2815 (2004); 10.1063/1.1802381

High quality Ge on Si by epitaxial necking

Applied Physics Letters 76, 3700 (2000); 10.1063/1.126754

High-quality Ge epilayers on Si with low threading-dislocation densities

Applied Physics Letters 75, 2909 (1999); 10.1063/1.125187

High-quality single-crystal Ge on insulator by liquid-phase epitaxy on Si substrates

Applied Physics Letters 84, 2563 (2004); 10.1063/1.1691175

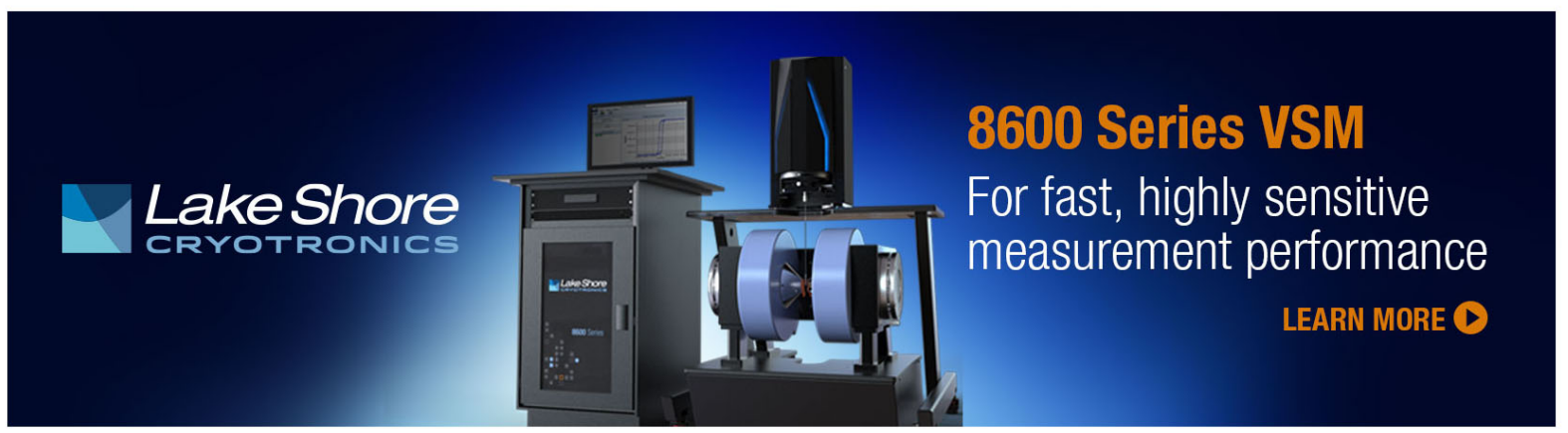




\title{
High quality single-crystal germanium-on-insulator on bulk Si substrates based on multistep lateral over-growth with hydrogen annealing
}

\author{
Hyun-Yong Yu, ${ }^{1, a)}$ Szu-lin Cheng, ${ }^{1}$ Jin-Hong Park, ${ }^{1,2}$ Ali K. Okyay, ${ }^{3,4}$ M. Cengiz Onbaşlı, ${ }^{3}$ \\ Burcu Ercan, ${ }^{2}$ Yoshio Nishi, ${ }^{1}$ and Krishna C. Saraswat ${ }^{1}$ \\ ${ }^{1}$ Department of Electrical Engineering, Stanford University, Stanford, California 94305, USA \\ ${ }^{2}$ Department of Electronics and Radio Engineering, College of Electronics and Information, \\ Kyung Hee University, Yongin-si/Gyeonggi-do 446-701, Republic of Korea \\ ${ }^{3}$ Department of Electrical and Electronics Engineering, Bilkent University, Ankara 06800, Turkey \\ ${ }^{4}$ UNAM, Institute of Materials Science and Nanotechnology, Bilkent University, Ankara 06800, Turkey
}

(Received 21 June 2010; accepted 21 July 2010; published online 9 August 2010)

\begin{abstract}
Germanium-on-insulator (GOI) is desired for high performance metal-oxide-semiconductor transistors and monolithically integrated optoelectronics. We demonstrate a promising approach to achieve single-crystal defect-free GOI by using lateral over-growth through $\mathrm{SiO}_{2}$ window. The dislocations due to the lattice mismatch are effectively terminated and reduced in $\mathrm{SiO}_{2}$ trench by selective area heteroepitaxy combined with hydrogen annealing. Low defect density of $4 \times 10^{6} \mathrm{~cm}^{-2}$ and low surface roughness of $0.7 \mathrm{~nm}$ (root-mean-square) on GOI are confirmed by plan-view transmission electron microscopy and atomic force microscopy analysis. In addition, the excellent metal-semiconductor-metal diode electrical characteristics fabricated on this GOI confirm Ge crystal quality. The selectively grown GOI structure can provide the monolithic integration of SiGe based devices on a Si very large scale integration (VLSI) platform. ( 2010 American Institute of Physics.
\end{abstract}

[doi:10.1063/1.3478242]

Germanium has been considered as a promising material for high performance complementary metal-oxidesemiconductor (CMOS) transistors and optoelectronic applications as it offers much higher and symmetric carrier mobility ${ }^{1-3}$ and smaller optical band gap ideal for $1.3-1.5 \mu \mathrm{m}$ wavelength commonly used in telecommunication. ${ }^{4}$ Germanium-on-insulator (GOI) can specially provide high performance MOS field-effect transistors by high-speed operation as well as low parasitic capacitance and immunity for short channel effects. Low-leakage junction current by thin-body GOI is also another benefit for channel materials with smaller band gap. ${ }^{5,6}$ Even more research efforts are directed toward the realization of on-chip optical signaling using Ge-based devices. There has been a surge in interest in SiGe based optoelectronics such as near IR detectors, ${ }^{7-9}$ Ge-based integrated optical modulators, ${ }^{10,11}$ and so on. The marriage of microelectronics to high performance photonics requires precise control and process compatibility. It is hence crucial to be able to grow high quality SiGe layers selectively on Si. For GOI structures, currently, many techniques such as oxidation-induced $\mathrm{Ge}$ condensation, ${ }^{12}$ laser annealing, ${ }^{13,14}$ solid-phase crystallization, ${ }^{15,16}$ metal-induced lateral crystallization, ${ }^{17}$ bonding, ${ }^{18}$ and lateral epitaxial growth ${ }^{19}$ have been introduced. However, these techniques to obtain GOI structures can be very complicated and have difficulty in achieving high-quality Ge films. In addition, the monolithic integration with Si based CMOS technology seems to be much more difficult. In other material, such as $\mathrm{GaN}$, lateral overgrowth technique has been demonstrated to effectively reduce dislocation densities on GaN films and was used to fabricate very high performance light emitting diodes and laser diodes. ${ }^{20-22}$

${ }^{a)}$ Electronic mail: yuhykr@stanford.edu.
In this paper, we demonstrate the lateral overgrowth of germanium on a $\mathrm{SiO}_{2}$ layer with multistep lateral overgrowth with hydrogen annealing (MLHA) technique. This MLHA technique yields Ge layers with very low dislocation density and surface roughness as confirmed by transmission electron microscope (TEM) analysis, and atomic force microscope (AFM) surface morphology studies. In addition, metalsemiconductor-metal (MSM) diode electrical characteristics are shown to confirm Ge crystal quality on $\mathrm{SiO}_{2}$.

$\mathrm{A} \mathrm{SiO}_{2}$ layer was thermally grown on p-type (100) $\mathrm{Si}$ substrate at $1100{ }^{\circ} \mathrm{C}$ that finally became the insulator layer of the GOI structure. The $\mathrm{SiO}_{2}$ film was then patterned by dry-etching followed by wet-etching. These etched vias became the growth windows for selective Ge epitaxy. The starting surface is very critical in epitaxy for single-crystal growth; therefore, the samples were etched in 50:1 $\left(\mathrm{H}_{2} \mathrm{O}: \mathrm{HF}\right)$ for $30 \mathrm{~s}$ and immediately loaded into an Applied Materials Centura epitaxial reactor. A hydrogen bake at $1000{ }^{\circ} \mathrm{C}$ was carried out to ensure that no native oxide remained on the $\mathrm{Si}$ surface between $\mathrm{SiO}_{2}$ walls. In order to increase the resulting films quality, a very thin $\mathrm{Si}$ epilayer was first grown for $90 \mathrm{~s}$ at $700{ }^{\circ} \mathrm{C}$ with dichlorosilane as the reaction species.

$\mathrm{Ge}$ growth on $\mathrm{Si}$ is surface reaction limited below $450{ }^{\circ} \mathrm{C}$ and is mass transport limited above. ${ }^{23}$ Therefore, low growth temperatures and pressures provide better selectivity between $\mathrm{Si}$ and $\mathrm{SiO}_{2}$. The reaction temperature was found to influence the growth rates of different crystal directions, as reported elsewhere. ${ }^{24}$ At $400{ }^{\circ} \mathrm{C},\langle 100\rangle$ normal direction was dominant at $30 \mathrm{~nm} / \mathrm{min}$ compared to $3 \mathrm{~nm} / \mathrm{min}$ in $\langle 113\rangle$ direction. This resulted in facet formation with $\{113\}$ surfaces. At elevated temperatures such as $600{ }^{\circ} \mathrm{C}$, growth rates for $\langle 100\rangle$ and $\langle 113\rangle$ directions were $60 \mathrm{~nm} / \mathrm{min}$ and $12 \mathrm{~nm} / \mathrm{min}$, respectively. Therefore, a careful design of the growth con- 
(a)

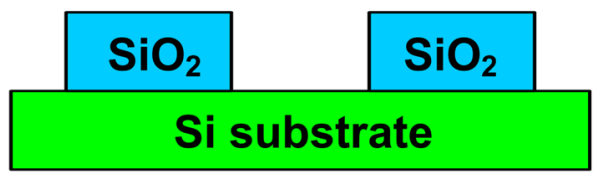

(b)

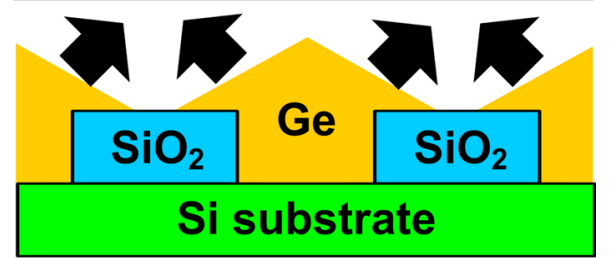

(c)

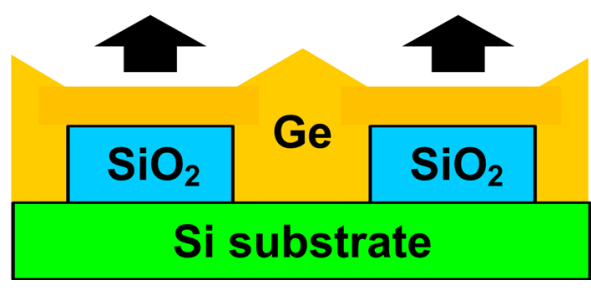

FIG. 1. (Color online) Illustration (a) of selective Ge growth at $400{ }^{\circ} \mathrm{C}$ on $\mathrm{Si}$ through openings in the $\mathrm{SiO}_{2}$ film. (b) Illustration of the growth mechanism at $400{ }^{\circ} \mathrm{C}$ before the films coalesce, (c) growth at $600{ }^{\circ} \mathrm{C}$ after coalescence.

ditions and a trade off between nucleation/selectivity and growth rate is required to achieve high quality GOI virtual substrates. Figure 1 shows the schematic of the lateral overgrowth Ge process. As shown Fig. 1(a), an initial lowtemperature growth is performed for higher $\mathrm{Si}-\mathrm{SiO}_{2}$ selectivity and reduced surface roughness. Once $\mathrm{Ge}$ layer becomes pyramidlike shape in the $\mathrm{SiO}_{2}$ trench, $\langle 311\rangle$ direction growth becomes dominant before coalescences in Fig. 1(b). After the coalescence happens, $\langle 100\rangle$ direction growth starts at the valley where two Ge growth fronts meet at specific condition. As shown in Fig. 1(c), due to a higher growth rate of $\langle 100\rangle$ direction compared to that of $\langle 311\rangle$ direction, the valley is quickly filled up and $\langle 100\rangle$ growth is dominant.

The initial Ge layer was grown at $400{ }^{\circ} \mathrm{C}$ with a partial pressure of $8 \mathrm{~Pa}$. Temperature in the chamber was raised to $825^{\circ} \mathrm{C}$ and the sample was annealed for $30 \mathrm{~min}$ in $\mathrm{H}_{2}$ ambient. This step is crucial to allow for surface reconstruction, reduce dislocation density and surface roughness. ${ }^{23,25}$ An

\section{(a)}

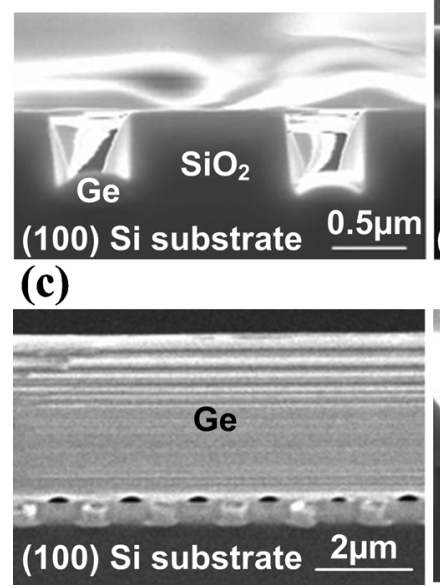

(b)

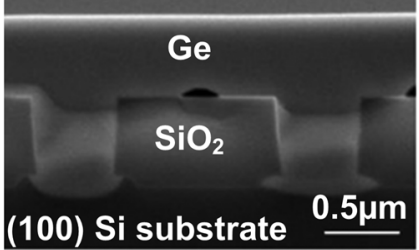

(d)

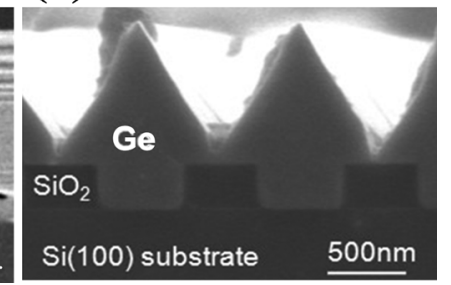

FIG. 2. Cross-sectional SEM images of the film after (a) growth at $400{ }^{\circ} \mathrm{C}$, (b) growth at $400{ }^{\circ} \mathrm{C}$ followed by $15 \mathrm{~min}$ at $600{ }^{\circ} \mathrm{C}$, (c) growth at $400{ }^{\circ} \mathrm{C}$ followed by $35 \mathrm{~min}$ at $600{ }^{\circ} \mathrm{C}$, and (d) growth at $400{ }^{\circ} \mathrm{C}$ for $1 \mathrm{~h}$.

(a)

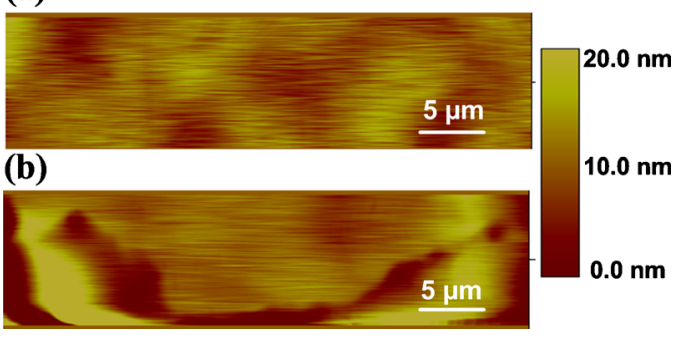

FIG. 3. (Color online) AFM scan images of $40 \times 10 \mu \mathrm{m}^{2}$ of the resulting thick film after low-temperature $\left(400^{\circ} \mathrm{C}\right)$ and high-temperature $\left(600{ }^{\circ} \mathrm{C}\right)$ growth (a) with and (b) without intermediate $\mathrm{H}_{2}$ anneal steps.

scanning electron microscopy (SEM) image of the sample after this step is shown in Fig. 2(a). After the coalescence, an additional growth step was performed at $600{ }^{\circ} \mathrm{C}$ for $15 \mathrm{~min}$ followed by $\mathrm{H}_{2}$ annealing at $825^{\circ} \mathrm{C}$, where the valley was filled up due to fast $\langle 100\rangle$ direction growth. However, as shown in Fig. 2(d), $\langle 100\rangle$ direction growth does not start at the valley after the coalescence of Ge films at $400{ }^{\circ} \mathrm{C}$ additional growth step. Figure 2(b) shows the resulting lateral over-lateral growth with the $400{ }^{\circ} \mathrm{C}$ and $600{ }^{\circ} \mathrm{C}$ growth temperature combination. The overall Ge layer thickness can be increased by longer growth at $600{ }^{\circ} \mathrm{C}$ as demonstrated in Fig. 2(c) for a growth time of $35 \mathrm{~min}$.

Large surface roughness and dislocation density are observed on as-grown samples as a result of the $4.2 \%$ lattice mismatch between $\mathrm{Si}$ and $\mathrm{Ge}$. The surface roughness reduction by annealing in hydrogen ambient at $825^{\circ} \mathrm{C}$ is attributed to hydrogen-mediated $\mathrm{Ge}$ diffusion and the reconstruction of the surface. ${ }^{23}$ Figure 3 shows $40 \times 10 \mu \mathrm{m}^{2}$ AFM scan images for two lateral overgrowth Ge films grown without hydrogen annealing and with MLHA. The surface of the sample with no annealing was significantly smoothened with MLHA. A very low rms surface roughness of $0.7 \mathrm{~nm}$ was achieved in MLHA GOI samples down from $3.5 \mathrm{~nm}$ for unannealed GOI films.

GOI film quality was investigated by TEM analysis. TEM images in Fig. 4 show very high quality Ge layers obtained on $\mathrm{SiO}_{2}$. Ge film grows selectively through a $500 \mathrm{~nm}$ wide window in the $\mathrm{SiO}_{2}$ layer. Defects were found only in the first $60 \mathrm{~nm}$ thick region from the $\mathrm{Ge}$ and $\mathrm{Si}$ interface. Previous efforts to obtain high quality epilayers on

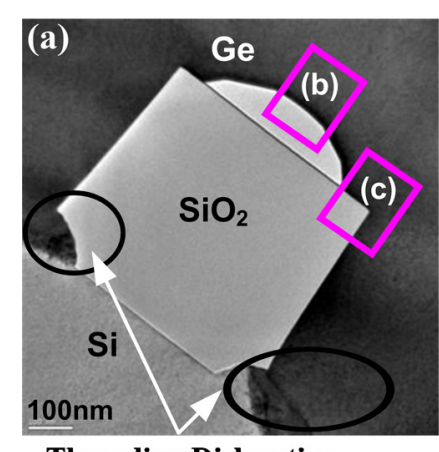

Threading Dislocation

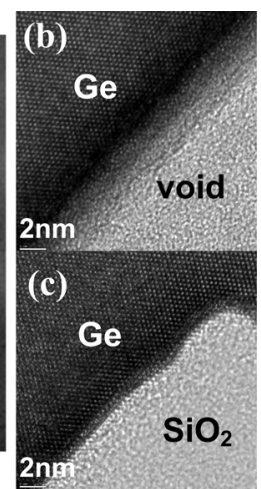

FIG. 4. (Color online) (a) Cross sectional TEM (XTEM) image of grown Ge film and the $\mathrm{SiO}_{2}$ mesa block. Defects and dislocations are in close vicinity of the Ge-Si interface while the rest of the film has very low defect density. [(b) and (c)] High resolution XTEM images of the Ge film on top of the $\mathrm{SiO}_{2}$ mesa and the void, showing defect free GOI layers. 

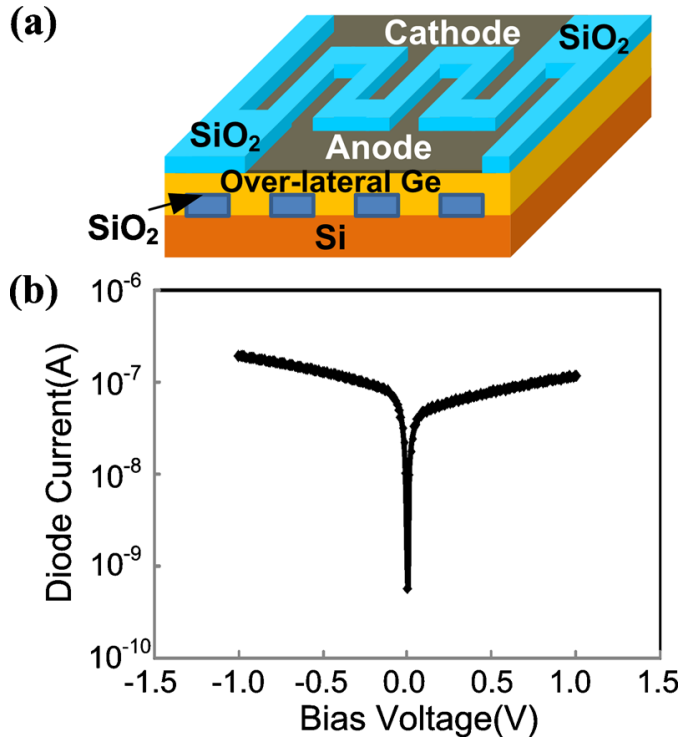

FIG. 5. (Color online) (a) Cross-section of MSM diode fabricated on overlateral grown Ge layer. (b) Current vs voltage characteristics of metalsemiconductor (Ti-Ge) Schottky diode on over-lateral grown GOI, both forward and reverse bias regions.

Si required a $500 \mathrm{~nm}$ or thicker buffer layers to confine the defects and dislocations. ${ }^{10,26}$ The hydrogen annealing technique reported in this work increases the surface mobility of $\mathrm{Ge}$ atoms leading dislocations to glide to $\mathrm{Ge} / \mathrm{SiO}_{2}$. In other word, the $\mathrm{SiO}_{2}$ sidewalls provide sinks for the dislocations. Once the Ge film thickness exceeds the height of the $\mathrm{SiO}_{2}$ trench, the lateral overgrowth of the film results in extremely single-crystal GOI layer. Owing to MLHA, the lateral overgrown Ge layer shows very low defect density, having a threading dislocation density count of $\sim 4 \times 10^{6} \mathrm{~cm}^{-2}$ based on the plan view TEM analysis. Figures 4(b) and 4(c) also show no visible defect where the growth fronts join. This is attributed to dislocation trapping within $\mathrm{SiO}_{2}$ trenches.

In order to confirm the high crystal quality of Ge layer over-laterally grown on $\mathrm{SiO}_{2}$ electrically, we fabricated simple MSM diode with interdigitated electrode width (5 $\mu \mathrm{m})$ and spacing $(5 \mu \mathrm{m})$ on the top of the over-lateral grown Ge layer. A $200 \mathrm{~nm}$ thick low-temperature chemicalvapor-deposited oxide layer was deposited at $400{ }^{\circ} \mathrm{C}$ for the purpose of surface passivation and isolation. This oxide layer was lithographically patterned and HF-etched, followed by metal electrode e-beam evaporation and photoresist lift-off process. Figure 5(a) illustrates a schematic diagram of the final structure. $15 \mathrm{~nm}$ thick Ti was used for controlling work function as well as achieving good adhesion, and then it was topped with $35 \mathrm{~nm}$ thick Au. Figure 5(b) presents the electrical current-voltage (I-V) characteristic of MSM (Ti-Ge-Ti) diode. Therefore, high quality Ge layer introduces low leakage current. ${ }^{27}$ Back-to-back Schottky diode behavior and low leakage current of $1.18 \times 10^{-7} \mathrm{~A}$ at $1 \mathrm{~V}$ as shown in Fig. 5 confirms the excellent Ge crystal quality of over-lateral grown GOI substrate.

In conclusion, we have demonstrated very high quality and defect free GOI with MLHA. The multistep $400 / 600{ }^{\circ} \mathrm{C}$ growth mechanism achieves single-crystal GOI The MLHA. This MLHA technique yields Ge layers with very low dislocation density and surface roughness. Such an approach promises the integration of SiGe based devices on a Si very large scale integration (VLSI) platform.

This work was performed at the Stanford Nanofabrication Facility (SNF) and was supported by MARCO Interconnect Focus Centers and the Stanford University INMP. The authors are grateful to Ted Kamins for helpful discussion.

${ }^{1}$ C. O. Chui, H. Kim, D. Chi, B. B. Triplett, P. C. McIntyre, and K. C. Saraswat, Tech. Dig. - Int. Electron Devices Meet. 2002, 441.

${ }^{2}$ C. H. Lee, T. Nishimura, N. Saido, K. Nagashio, K. Kita, and A. Toriumi, Tech. Dig. - Int. Electron Devices Meet. 2009, 457.

${ }^{3}$ H.-Y. Yu, M. Ishibashi, J.-H. Park, M. Kobayashi, and K. C. Saraswat, IEEE Electron Device Lett. 30, 675 (2009).

${ }^{4}$ K. Saraswat, D. Kim, T. Krishnamohan, D. Kuzum, A. Okyay, A. Pethe, and H.-Y. Yu, ECS Trans. 16(10), 3 (2008).

${ }^{5}$ S.-I. Takagi, Dig. Tech. Pap. - Symp. VLSI Technol. 2003, 115.

${ }^{6}$ T. Maeda, K. Ikeda, S. Nakaharai, T. Tezuka, N. Sugiyama, Y. Moriyama, and S. Takagi, Thin Solid Films 508, 346 (2006).

${ }^{7}$ M. Oehme, J. Werner, E. Kasper, M. Jutzi, and M. Berroth, Appl. Phys. Lett. 89, 071117 (2006).

${ }^{8}$ D. Ahn, C. Hong, J. Liu, W. Giziewicz, M. Beals, and L. C. Kimerling, Opt. Express 15, 3916 (2007).

${ }^{9}$ H.-Y. Yu, S. Ren, W. S. Jung, A. K. Okyay, D. A. B. Miller, and K. C. Saraswat, IEEE Electron Device Lett. 30, 1161 (2009).

${ }^{10}$ Y. H. Kuo, Y. Lee, Y. Ge, S. Ren, J. E. Roth, T. I. Kamins, D. A. B. Miller, and J. S. Harris, Nature (London) 437, 1334 (2005).

${ }^{11}$ O. Fidaner, A. K. Okyay, J. E. Roth, R. K. Schaevitz, Y. H. Kuo, K. C. Saraswat, J. S. Harris, and D. A. B. Miller, IEEE Photonics Technol. Lett. 19, 1631 (2007).

${ }^{12}$ S. Nakaharai, T. Tezuka, N. Sugiyama, Y. Moriyama, and S. Takagi, Appl. Phys. Lett. 83, 3516 (2003).

${ }^{13}$ H. Watakabe, T. Sameshima, H. Kanno, T. Sadoh, and M. Miyao, J. Appl. Phys. 95, 6457 (2004).

${ }^{14}$ W. Yeh, H. Chen, H. Huang, C. Hsiao, and J. Jeng, Appl. Phys. Lett. 93, 094103 (2008).

${ }^{15}$ I. Tsunoda, A. Kenjo, T. Sadoh, and M. Miyao, Appl. Surf. Sci. 224, 231 (2004)

${ }^{16}$ C. Y. Tsao, J. W. Weber, P. Campbell, P. I. Widenborg, D. Song, and M. A. Green, Appl. Surf. Sci. 255, 7028 (2009).

${ }^{17}$ J.-H. Park, P. Kapur, H. Peng, and K. C. Saraswat, Appl. Phys. Lett. 91, 143107 (2007).

${ }^{18}$ M. N. Kamalasanan, S. Chandra, P. C. Joshi, and A. Mansingh, Appl. Phys. Lett. 59, 3547 (1991).

${ }^{19}$ V. D. Cammilleri, V. Yam, F. Fossard, C. Renard, D. Bouchier, P. F. Fazzini, L. Ortolani, F. Houdellier, and M. Hytch, Appl. Phys. Lett. 93, 043110 (2008).

${ }^{20}$ H. Marchand, X. Wu, J. Ibbetson, P. Fini, P. Kozodoy, S. Keller, J. Speck, S. DenBaars, and U. Mashra, Appl. Phys. Lett. 73, 747 (1998).

${ }^{21}$ A. Usui, H. Sunakawa, A. Sakai, and A. Yamaguchi, Jpn. J. Appl. Phys., Part 2 36, L899 (1997).

${ }^{22}$ S. Nakamura, M. Senoh, S. Nagahama, N. Iwasa, T. Yamada, T. Matsushita, H. Kiyoku, Y. Sugimoto, T. Kozaki, H. Umemoto, M. Sano, and K. Chocho, Jpn. J. Appl. Phys., Part 2 36, L1568 (1997).

${ }^{23}$ A. Nayfeh, C. O. Chui, and K. C. Saraswat, Appl. Phys. Lett. 85, 2815 (2004).

${ }^{24}$ J.-S. Park, J. Bai, M. Curtin, B. Adekore, M. Carroll, and A. Lochtefeld, Appl. Phys. Lett. 90, 052113 (2007).

${ }^{25}$ S. Kobayashi, M. Cheng, A. Kohlhase, T. Sato, J. Murota, and N. Mikoshiba, J. Cryst. Growth 99, 259 (1990)

${ }^{26}$ H. Luan, D. Lim, K. Lee, K. Chen, J. Sandland, K. Wada, and L. Kimerling, Appl. Phys. Lett. 75, 2909 (1999).

${ }^{27}$ A. K. Okyay, A. M. Nayfeh, T. Yonehara, A. Marshall, P. C. McIntyre, and K. C. Saraswat, Opt. Lett. 31, 2565 (2006). 